\title{
Contingent Valuation Method (CVM) to Measure the External Cost From the Pollution of the Lagoon of Lefkas Island in Greece
}

\author{
Odysseas Kopsidas \\ Technological Educational Institute of Thessaloniki, Thessaloniki, Greece \\ Leonidas Fragkos-Livanios \\ Hellenic Army Academy, Vari, Greece
}

\begin{abstract}
The authors use the WTP (willingness to pay) method to compute approximate external economies in the case of restoration of the natural environment at Lagoon of Lefkas Island in Greece. The preservation/restoration of natural environment is frequently entailing excessive cost (paid by people through taxation), while it is a source of additional income for both the state and the people, mainly due to tourism. Since the evaluation of this good cannot be in market terms, the authors apply here a modified version of the contingent valuation method (CVM), in order to investigate the significance that people assign on goods and how much they might be WTP for supporting activities concerning the preservation/restoration of the Lagoon of Lefkas Island. The results demonstrate an increased awareness and sensitivity on environmental issues regarding the lagoon on behalf of the public and a limited WTP, with an average of approximately 20 euros per month. The greater part of the bill should fall on the local and central governments, for a viable and successful remediation and preservation of the lagoon.
\end{abstract}

Keywords: willingness to pay (WTP), willingness to accept (WTA), environmental protection, non-market resources

Environmental science has shown that environmental externalities can be pervasive and affect individuals across space and time dimensions (Sarraf, Larsen, \& Owaygen, 2004). Suggested solutions to that externality problem include the use of taxes—best known as Pigouvian taxes after the economist who proposed them—and regulations. To evaluate these externalities, tools contributed from economic theory are necessary. Concepts such as externalities, public goods, and welfare economics dominate the description and solution strategies. Welfare economics provided the theoretical foundations for considering the environment and natural resources as goods for which society and individuals' willingness to pay could be measured. Along with the historical development of the environmental applications of economic theory, the use of valuation became more and more important. A famous example is that of the Exxon-Valdez oil spill in Alaska in 1989 where the compensation to

Corresponding author: Odysseas Kopsidas, M.Sc., Ph.D. candidate, Department of Agricultural Technology, Technological Educational Institute of Thessaloniki, Thessaloniki, Greece; research fields: environmental economics and non-marketable goods cost evaluation. E-mail: odykopsi@yahoo.gr.

Leonidas Fragkos-Livanios, lecturer, Division of Natural Sciences and Applications, Hellenic Army Academy, Vari, Attiki, Greece; research fields: bioremediation and proteomics. E-mail: leonfragkos@yahoo.co.uk. 
affected individuals was estimated by placing values on the externalities. Balancing winners and losers of a policy would eventually be made easier by the use of valuation techniques (Bolt, Ruta, \& Sarraf, 2005).

Lefkas is one of the islands located in Ionian Sea in Greece. The Lagoon of Lefkas Island and the Lagoon of the Straits are of great natural beauty. They are included in the network Natura 2000 as protected areas with special ecological importance. The area of the Lagoon of Lefkas Island is an important migratory bird station, designated by the RAMSAR treaty as a wetland of international importance, a habitat to a number of rare bird species such as swans herons, lapwings, and different kinds of seagulls, ducks, and geese. Inside the lagoon, there is "ivari", farms with special traditional reed mats, where fish live and grow in natural conditions. At the edges grow reeds, while in the middle, there is a characteristic narrow strip of land (louronisida) with reeds and rushes. There are also two old salt flats, from which one has unfortunately turned into a wasteland. The area is crossed by boats and small boats passing to Lefkas Island. There are also small coves for boats on the west side, near the town.

The survey examined, among other factors, the attitude of citizens toward the general environmental problems of the area and the benefits that would derive from restoring the lagoon's ecosystem.

\section{Implementation}

The authors estimate approximately the size of the external economic cost from the polluted lagoon in Lefkas Island in Greece by the contingent valuation method (CVM) (Batzias, 2008; Batzias, 2010; Brown, 2005). CVM is a survey-based technique, frequently used in experimental economics, especially useful for the valuation of non-market resources/goods/services, and environmental objects (of aesthetic, historic, scientific, or social value), such as preservation of the physical and anthropogenic environment (Batzias \& Kopsidas, 2010). The basic dependent variables used in CVM are: (1) willingness to pay (WTP), which is the maximum monetary amount that an individual would pay to obtain/preserve a good; (2) willingness to accept (WTA) compensation, which is the minimum monetary amount required to relinquish the good (Batzias \& Markoulaki, 2002; Liao, 1994; Menard, 2001). Therefore, WTP provides a purchase price, relevant for valuing the proposed gain of the good while WTA provides a selling price, relevant for valuing the proposed loss of the good. According to classic economic theory, a significant difference between WTP and WTA should not occur, on condition that there is no transaction cost, perfect information about goods/services and corresponding prices; (3) no income effect; and (4) a market that engenders truthful revelation of preferences. Although these conditions were generally met in several economic experiments that used inexpensive market goods with readily available substitutes, the ratios WTA/WTP obtained were significantly greater that unity (Rayleigh, 1915). This result was attributed to the fact that participants in these experiments lacked market experience (Allais, 1952).

\section{Results and Discussion}

In order to ensure the collection of a representative sample from all social and occupational classes, interviews were conducted throughout the day between 8:30 a.m. and 9:00 p.m. It is worth mentioning that a small percentage of people who were selected to participate in the interview in person refused to do so. It is reported that of the 95 people selected, 15 (15.8\%) refused to participate. In order to render the analysis and statistical processing possible, the questionnaires collected were coded accordingly.

The financial profile of the sample was generated by means of the notion the interviewees have for their own income, how they place themselves financially in comparison to the rest of the residents of the area. 
Interviewees were asked to rank their household income in relation to the average of the area. Even though it was not the first question on the questionnaire, it is shown here first since it is an important bias, as tolerance to pollution varies with the socioeconomic status—-true and perceived of citizens (see Figure 1).

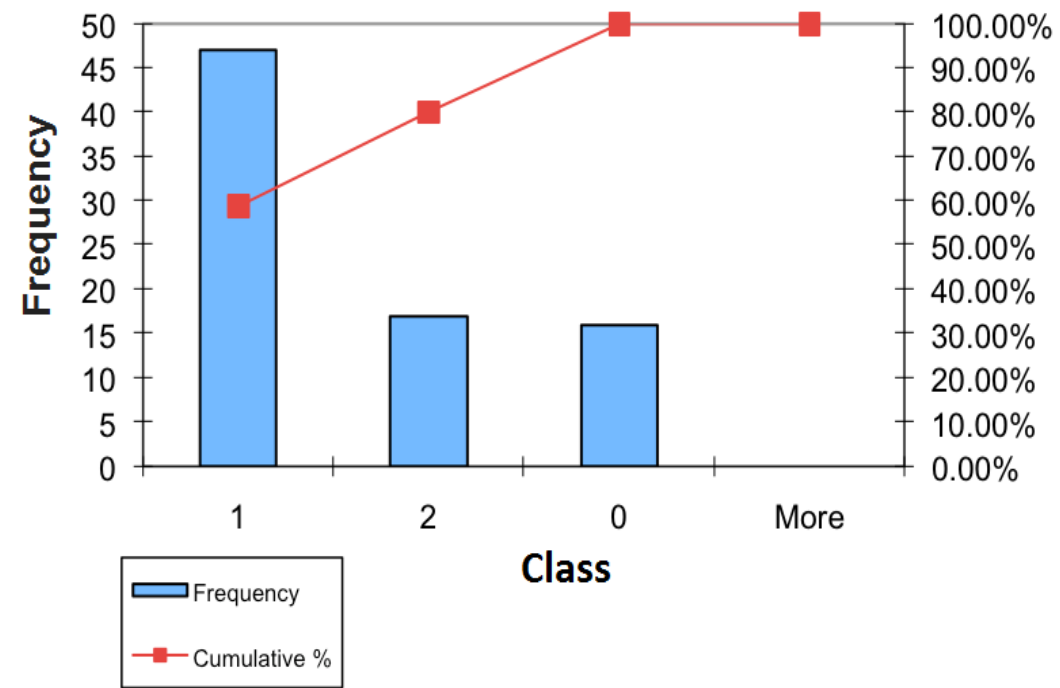

Figure 1. How do you rank your houshold annual income, compared to the average of the wider area of Lefkas? Notes. 0 -almost the same; 1 -lower; 2-higher.

The first question of the questionnaire examined whether the interviewee had visited the lagoon during the last year. The respondents had to indicate the reason for their visit. The purpose of this question is to record the activities taking place in the lagoon. From these histograms, the main reason for someone to visit the lagoon emerged and that was for walking as a large percentage (88.75\%) of the population said they visited the lagoon for this reason. The following histogram shows the frequency of respondents who said they visited the last 12 months.

In Figure 2, it is shown that $21.25 \%$ of the respondents who visited the lagoon for walking, have visited the lagoon 53-104 times in the last 12 months.

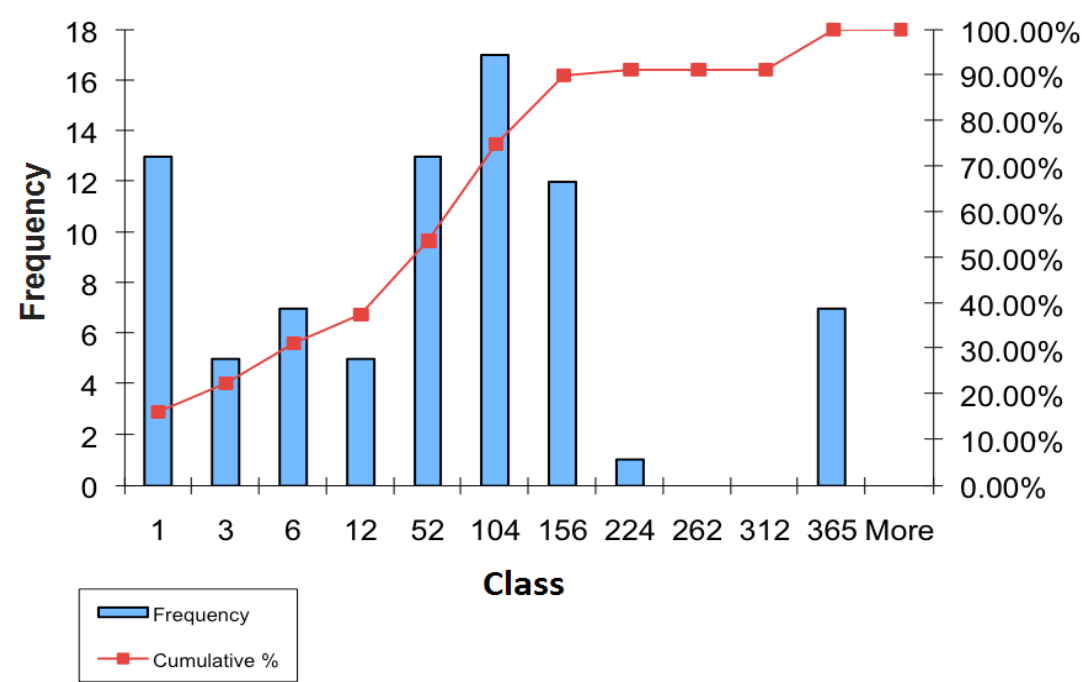

Figure 2. Frequency histogram for "walking”. Notes. On x-axis-number of visits of the last 12 months; on $\mathrm{y}$-axis-number of respondents. 
Surprisingly, the results showed that a small number of individuals visit the lagoon for boating. Only three respondents said they did, with a frequency presented in Figure 3.

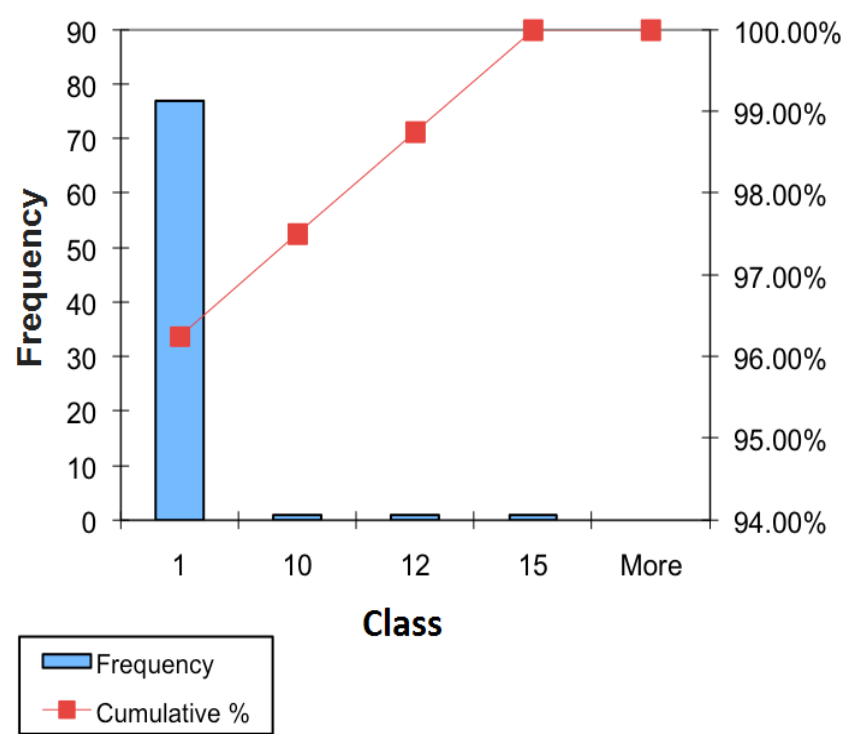

Figure 3. Frequency histogram for "boating”. Notes. 1-never; 10, 12, and 15 are reffering to the actual number of visits; on the y-axis - the number of respondents.

The frequency for exercise is greater, with 15 people declaring that they visited the lagoon for this reason (see Figure 4).

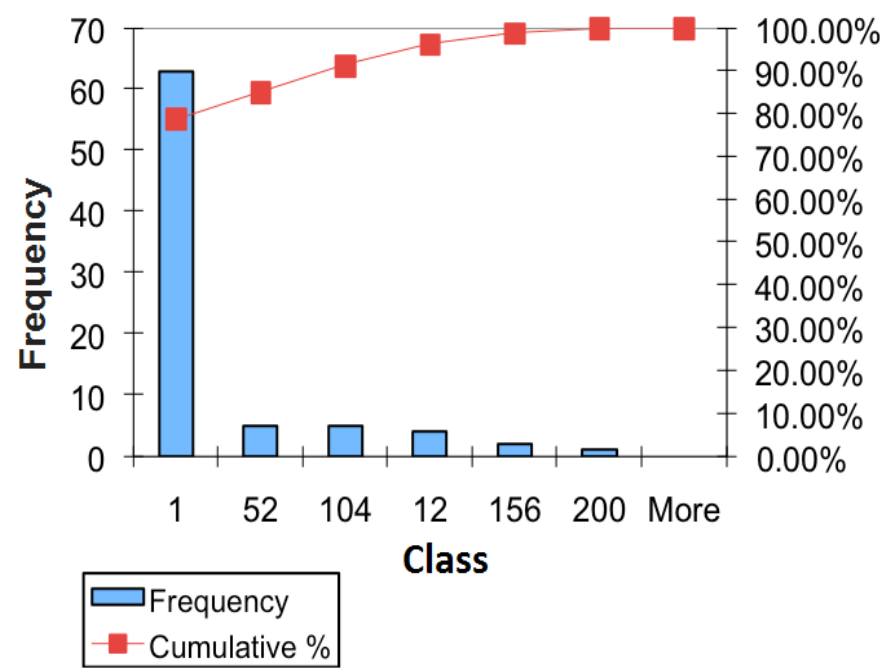

Figure 4. Frequency histogram for "exercise”. Notes. 1-never; 12, 52, 104, 156, and 200 are reffering to the actual number of visits; on the y-axis—-the number of respondents.

Further, two people replied that they have visited the lagoon for swimming, with one interviewee declaring 10 visits and other 30 in the last 12 months (see Figure 5).

Another reason for visiting the lagoon is fishing. Five of the respondents reported having visited the lagoon for fishing (see Figure 6).

Seven of the respondents reported having visited the lagoon for other reasons (see Figure 7). 


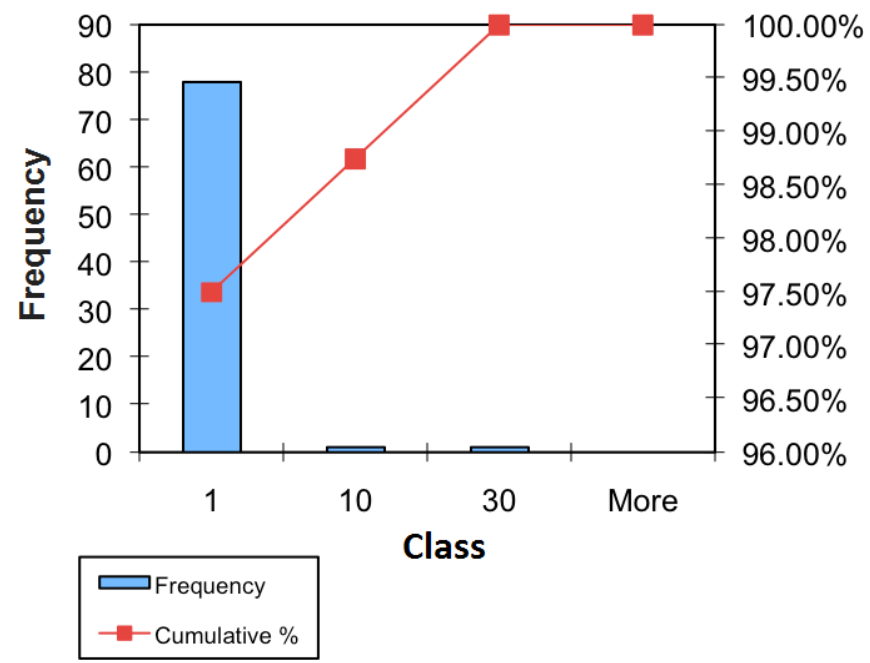

Figure 5. Frequency histogram for "swimming”. Notes. 1-never. 10 and 30 are reffering to the actual number of visits.
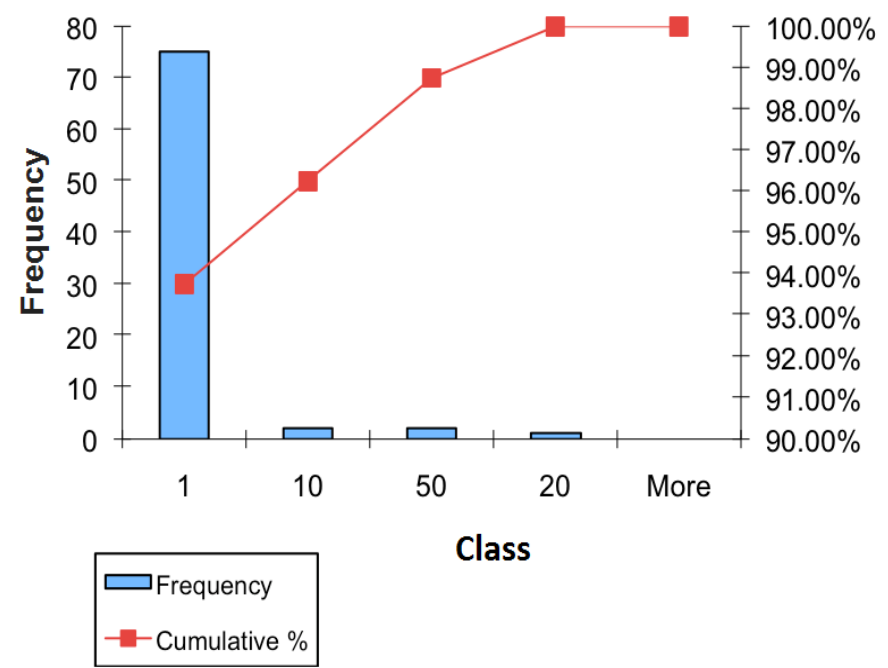

Class

Figure 6. Frequency histogram for "fishing”. Notes. 1-never; 10, 20, and 50 are reffering to the actual number of visits.

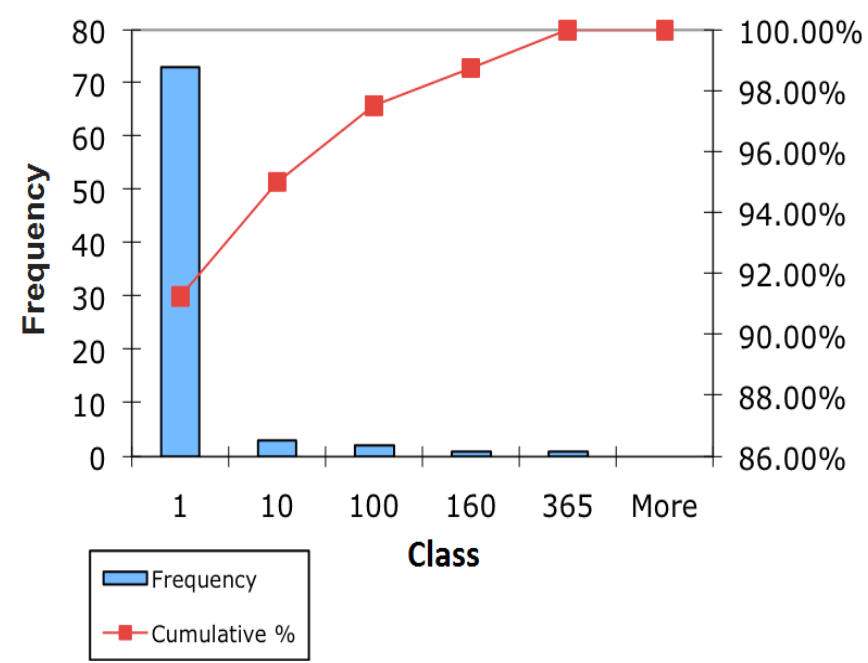

Figure 7. Frequency histogram for "other reasons”. Notes. 1-never; 10, 100, 160, and 365 reffer to the actual number of visits. 
All the interviewees answered that they have heard or read something about the pollution of the lagoon. In order to generate a profile regarding the source of information, the interviewees were asked to indicate the source they have heard or read something about the pollution of the lagoon. The vast majority (51\%) responded that they had been informed through television. A significant portion of the sample were updated by newspapers/magazines or through friends, $49 \%$ and $46 \%$ respectively, followed by radio with $31 \%$ and the internet by $26 \%$, with only $13 \%$ by means of briefings, while $5 \%$ said they learned otherwise (see Figure 8 ).

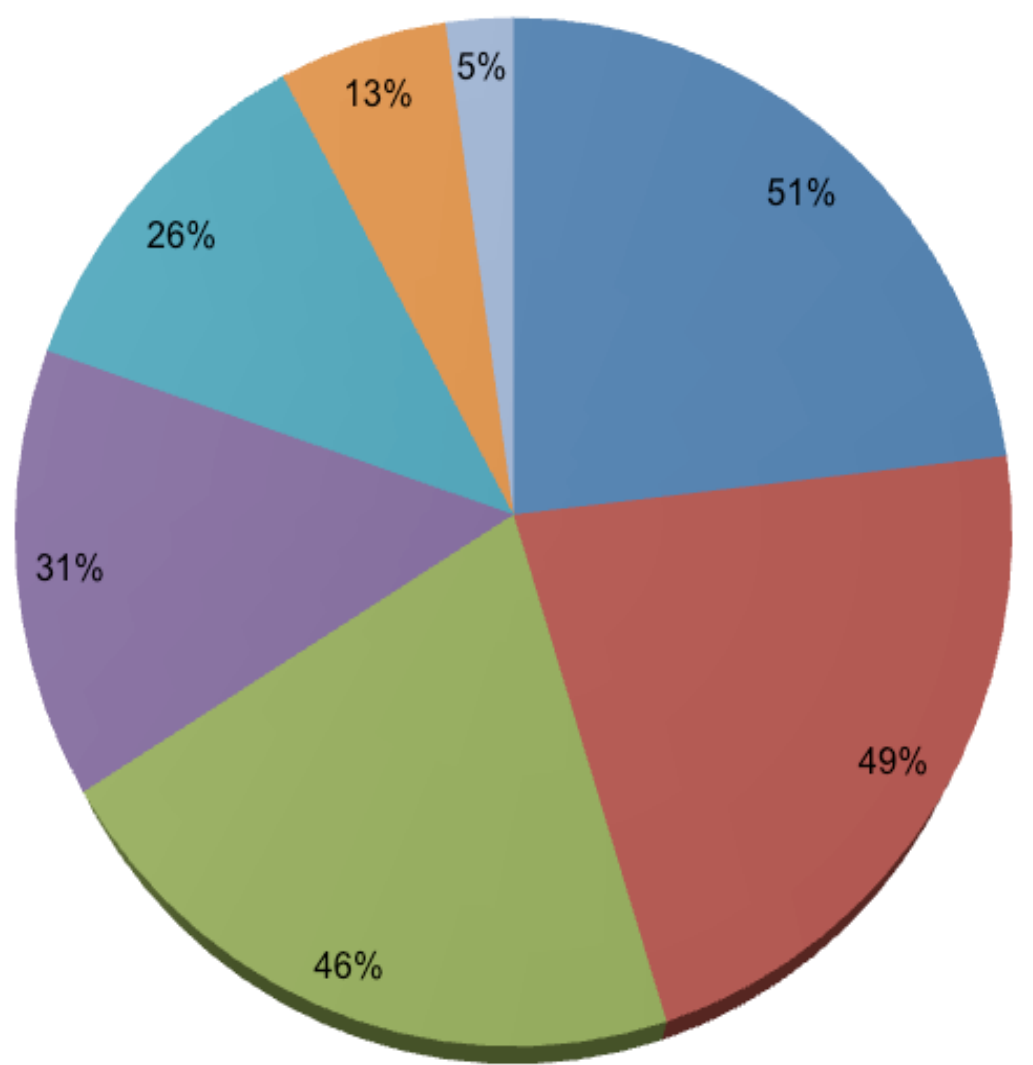

Figure 8. Source of information regarding the state of the lagoon. Notes. 51\%—television; 49\%-press (news papers and journals); 46\%—from friends; 31\%—radio broadcastings; 26\%—internet; 13\%—briefings on enviromental issues; $5 \%$-other sources.

The third question asks the interviewees to characterize the environmental situation of the lagoon. The majority (52.5\%) characterize the situation of the lagoon "moderate", followed by "poor" (40\%) as opposed to a low 7.5\% that rank it as "good" and zero answers for the "very good" option (see Figure 9).

The fourth question referred to regional environmental problems and specifically, what in the opinion of interviewees - are the top three environmental issues (in order of importance). Pollution is considered as the most important environmental issue of the lagoon with $20 \%$.

Next, the interviewees are asked to choose the main cause of the environmental problems of the lagoon. Thirty percent (30\%) of them chose the indifference of the state as the main cause. An equal fraction of the sample (30\%) have pointed the weakness of the local government. The remainder (40\%) is shared equally between the "ignorance and indifference of citizens" and "growth without environmental planning" (see Figure 10). 

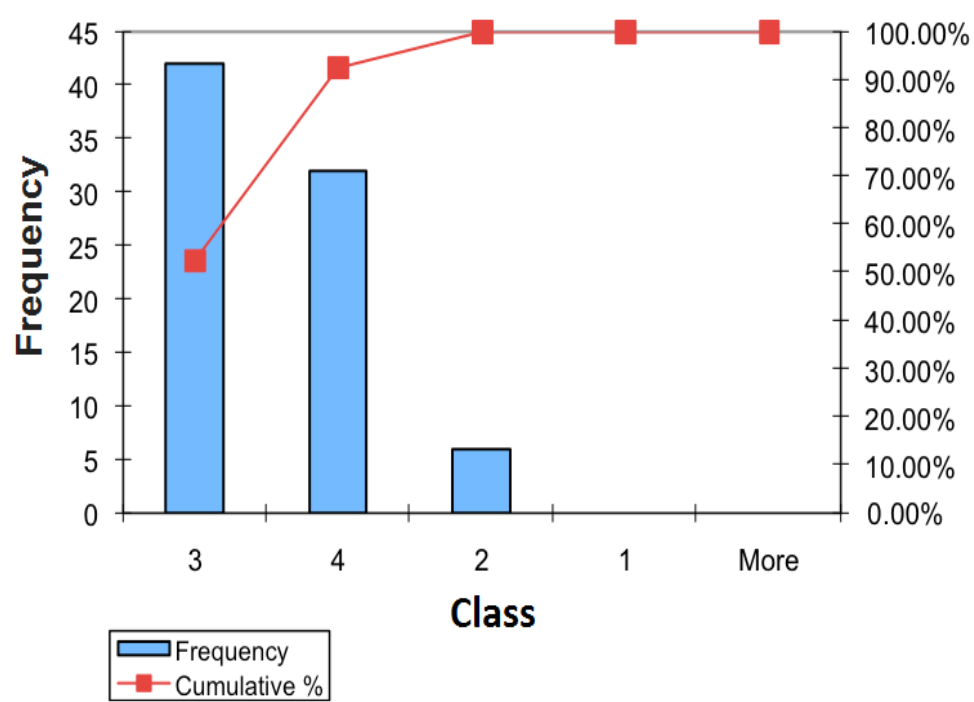

Figure 9. Opinions on the state of the lagoon. Notes. 1—very good; 2—good; 3-moderate; 4—poor.

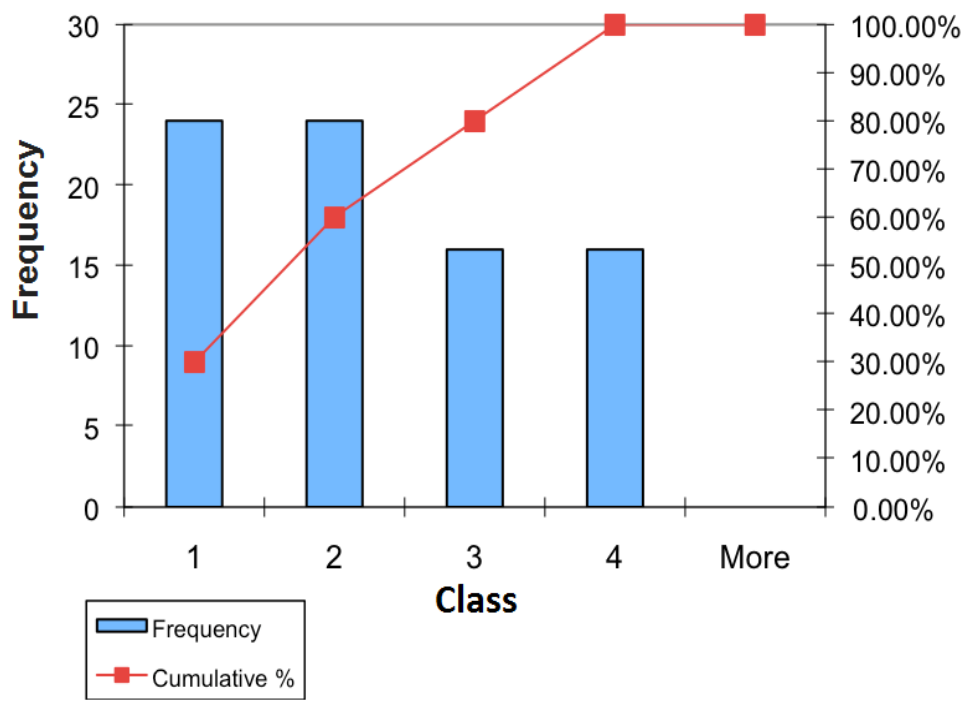

Figure 10. What is the main reason behind the envirommental challenges threatening the lagoon? Notes. 1-state indiference for enviromental issues; 2-weak municipal governance; 3-ignorance and indiference of the citizens; 4-development without enviromental planing.

When asked to describe the effort made by the relevant authorities for the protection of the lagoon, the majority of the population (76.25\%) described the work of relevant bodies as "no good" and $22.5 \%$ described it as "moderately good”. One person refused to answer this question (see Figure 11).

The seventh question asked the respondents to answer with yes or no, whether they were members of an environmental organization. A small percentage, $10 \%$, answered positively to this question, with the majority not being a member of an environmental organization (see Figure 12).

Further, the perception of the population regarding participation in improving the condition of the pond was probed. The majority believe that the funding should derive mainly by means of private donations (see Figure 13). 


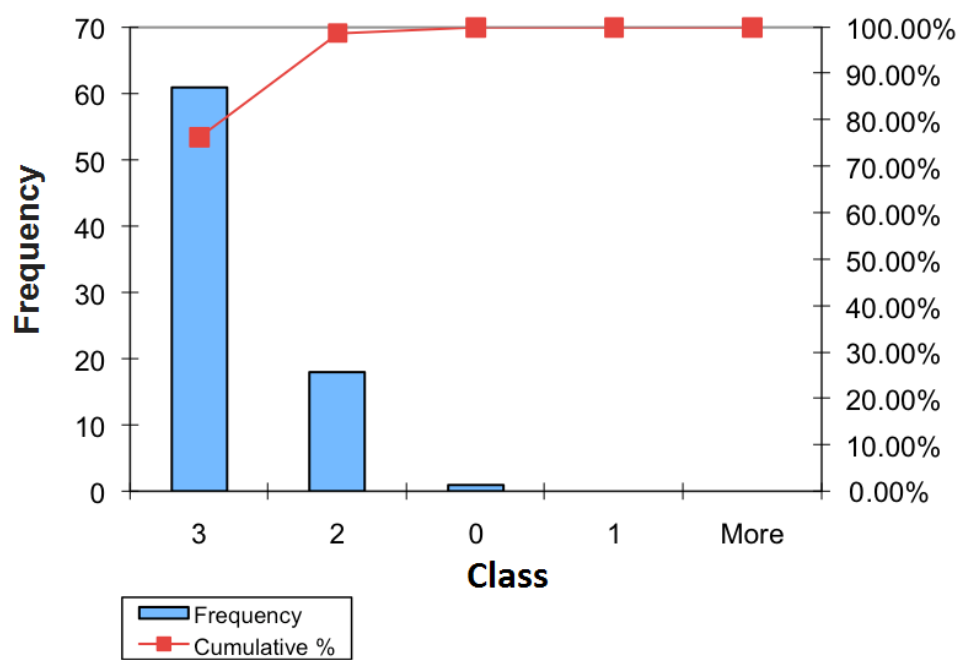

Figure 11. Frequency histogram of answers on the the effort made by the relevant authorities for the protection of the lagoon. Notes. 0-no answer; 1—good; 2-moderately good; 3-no good.

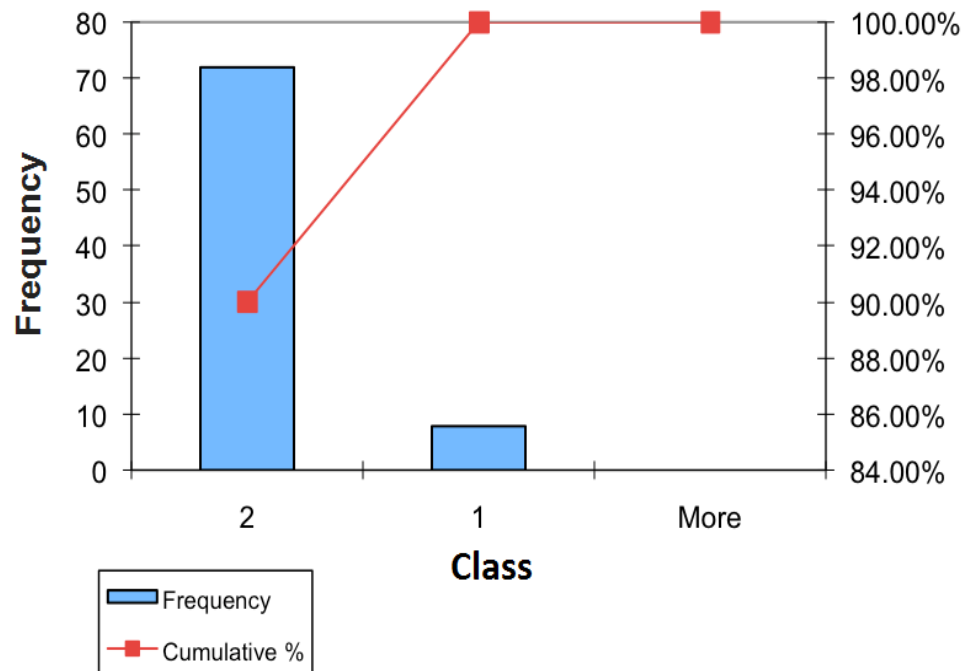

Figure 12. Frequency histogram on answers on the question “Are you a member of an enviromental organisation?”. Note. 1-Yes; 2-No.

Seemingly contradictory though are the results when the ratio of funding between the local community and the central government are probed. The relevant question reads: "For each $€ 100$ needed to improve the situation of the lagoon, how much should derive from the local community and how much from the central government, through general taxation?” (see Figure 14). The contradiction between the two sets of answers shows the public confusion regarding participation in a financial scheme. It is likely that the term "private donation" was associated more to companies and industries and much less to citizens. It is also apparent the ease with which the citizens identify the obligations of the state and the central government, especially when it comes to money. The message is clear: The central government has to pay more than the local community. The burden of environmental remediation and preservation should fall on the sum of the taxpayers of the country and not only on the local population. 


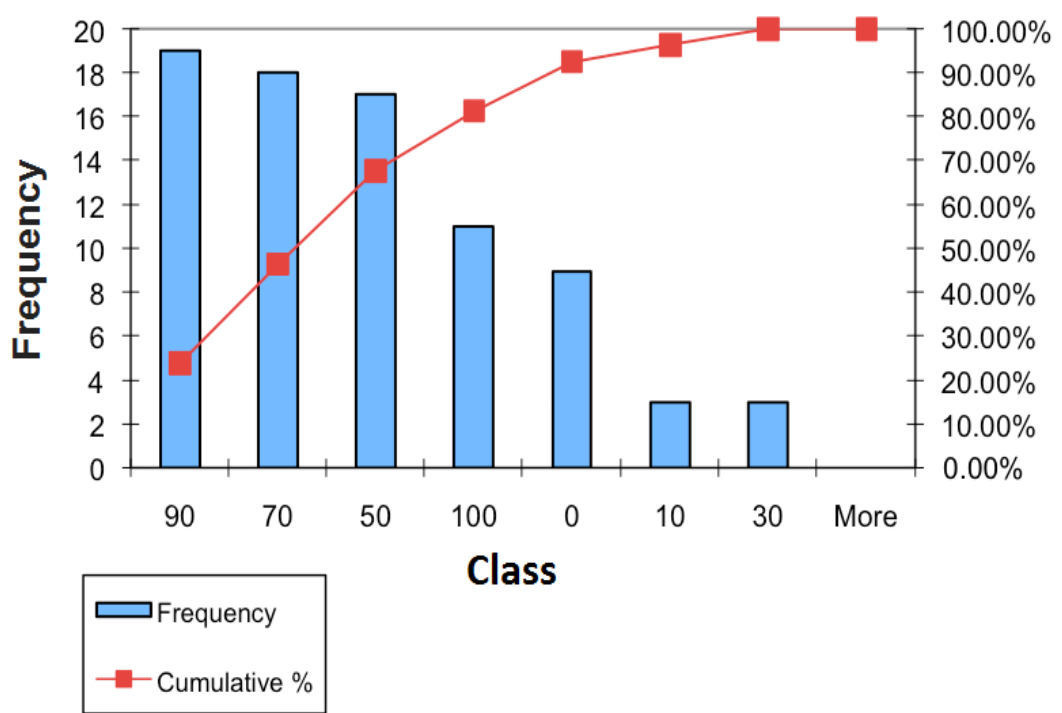

Figure 13. Frequency histogram from the answers on the question "What fraction of the funding necessary for the enviromental remediation or preservation of the lagoon should derive from private donations, from individual or companies?”. Notes. Numbers on x-axis represent the percentage of the fraction of the total funding deriving from donations. Namely, 100 — total should derive from private donations; 0 —nothing should derive from private donations.
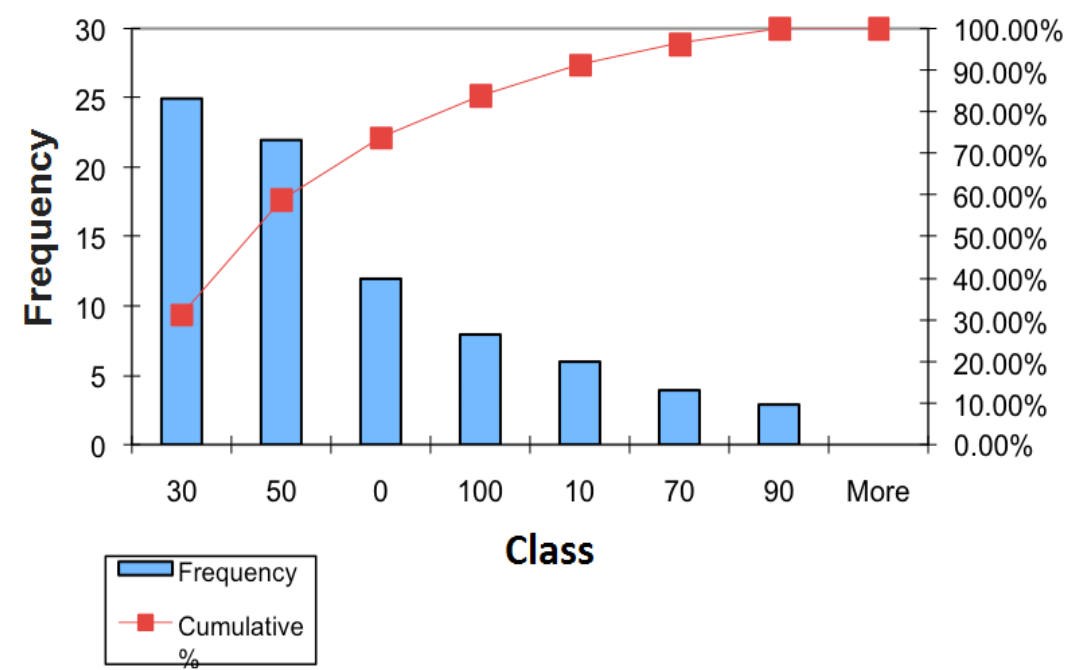

Class

Figure 14. Answers on the question "For each $€ 100$ needed to improve the situation of the lagoon, how much should derive from the local community and how much from the central government, through general taxation?”. Notes. Amounts on the plot refer to the contribution of local community. For example, for class 30, 25 individuals suggest that the local community should contribute $30 \%$ of the total amount.

The next question refers to the importance of protecting the lagoon. The $93.75 \%$ of interviewees answered that it is "very important" and only the $5 \%$ of them answered that it is "quite important". Out of the 80 interviewees, only one considers the protection of the lagoon "moderately significant” (see Figure 15).

The next question is pivotal to the investigation. It involves the willingness or refusal to pay. Participants were asked to state the maximum amount they could offer monthly and for a year's period as a contribution toward the improvement of the lagoon state, in case the existing funds by the central and local government remain unchanged. The bulk of the population, with $71.75 \%$, is willing to give $€ 5-20$ per month. Notably, out of 80 people surveyed, eight refused to contribute any amount to improve the lagoon (see Figure 16). 


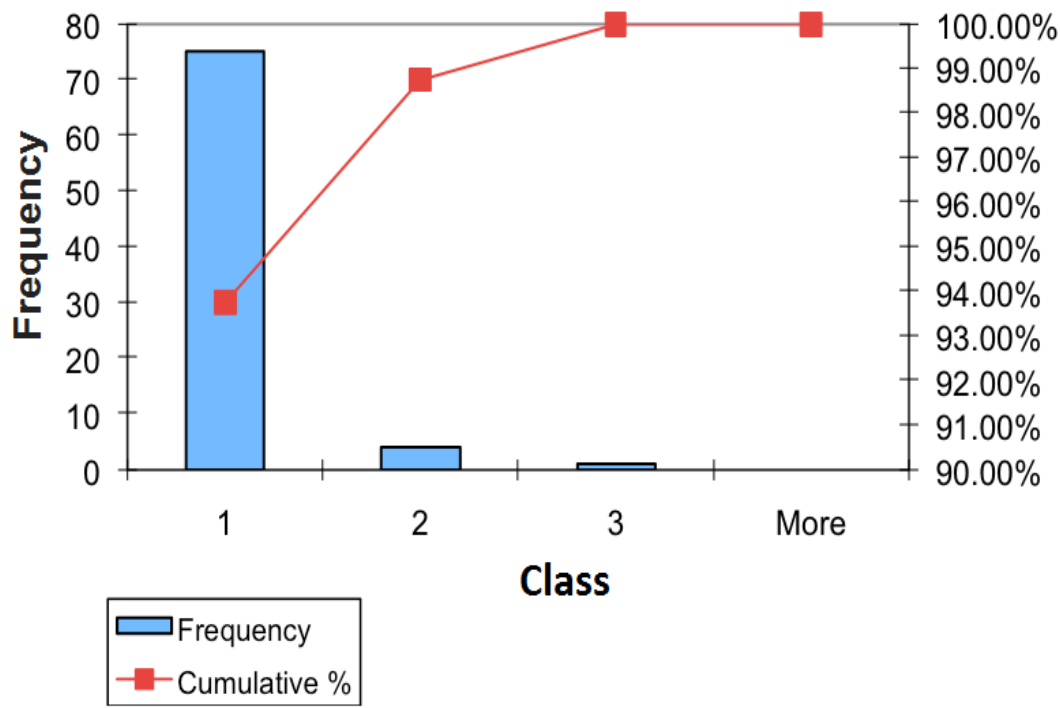

Figure 15. The importance of protecting the lagoon. Notes. 1—very important; 2-quite important; 3-moderately significant; the class "more" is irrelevant.

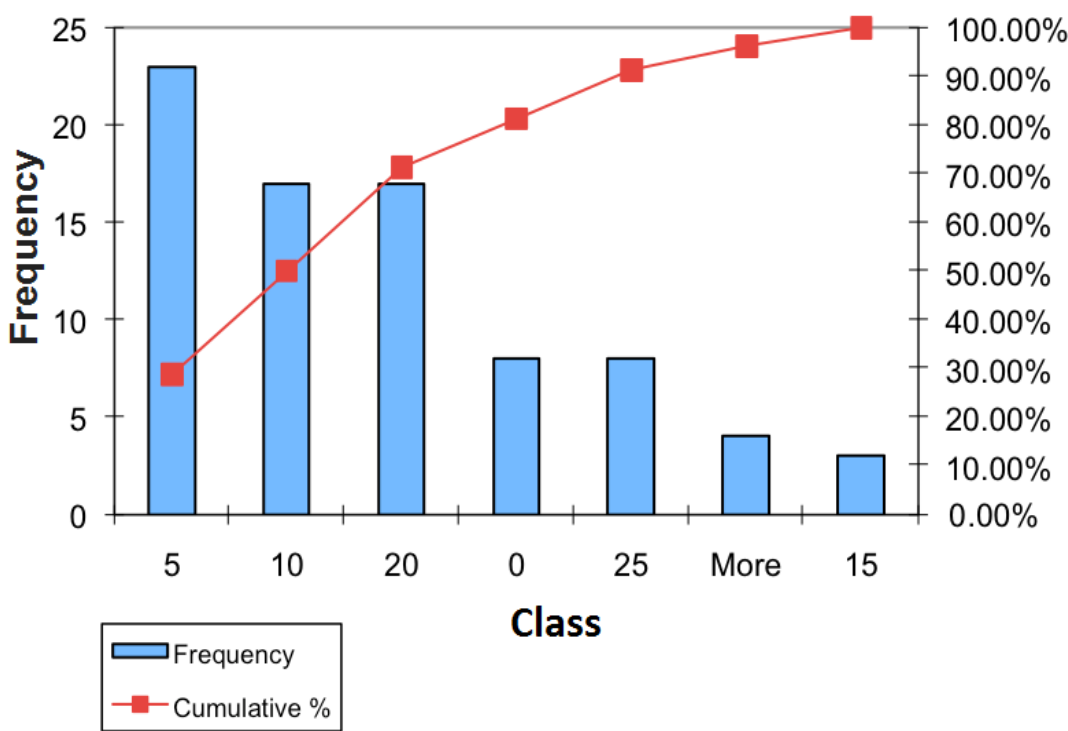

Figure 16. What is the maximum amount in euros per month that you are willing to donate for a year for the preservation of the lagoon, taking into acount that the existing municipal and state funding cannot increase. Note. On $\mathrm{x}$-axis-the amount in euros.

To demonstrate how locality affects WTP, the results from the residents near the lagoon are presented separately (see Figure 17).

The WTA for residing by the lagoon was probed, assuming the situation would remain as it is, unchanged and without any plans for remediation (see Figure 18). The vast majority would accept no compensation for accepting the current state. Measures should be implemented toward the remediation of the lagoon.

Regarding the practice of certain small industries to dispose treated liquid waste into the lagoon, the preferable answer was daily checks performed by a municipality employee. The inspectors will assess the quality of the waste water and decide whether it meets legislative standards for safe disposal in the lagoon or 
not.

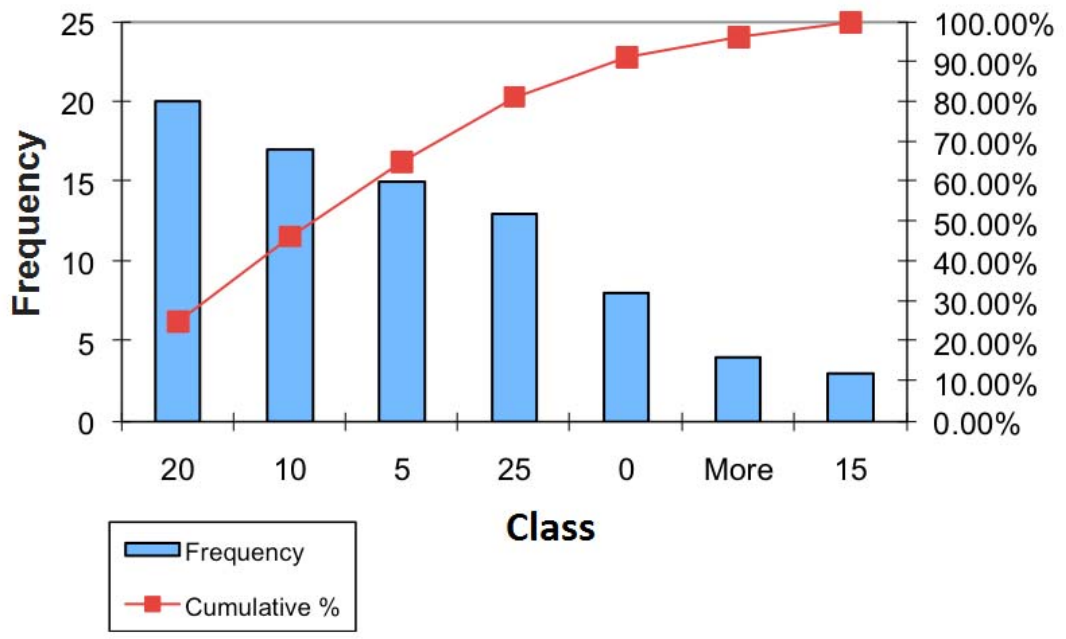

Figure 17. The same as Figure 16 but only for residents.

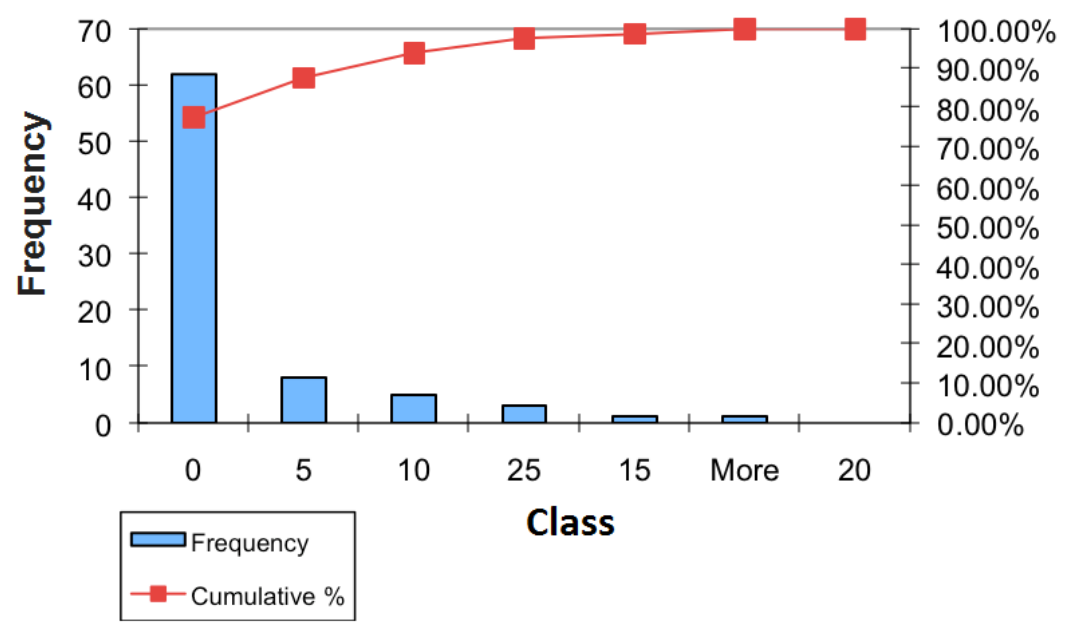

Figure 18. Answers to question (for non-residents): If you moved to live by the lagoon, what is the smallest amount you would accept as compensation to accept the current situation as it is, without any objection?

The last part of the questionnaire consisted of 13 questions of demographic nature. These questions are necessary for statistical classification. They refer to gender, age, marital, and employment status, education level and data on income and permanent residence of participation. The relevant results are shown on the following graphs, with some details regarding every question.

The distribution between the sexes is balanced, with $48.75 \%$ for men and $51.25 \%$ for women (see Figure 19).

The age distribution of the sample is shown in Figure 20, where: (1) 16-25; (2) 26-35; (3) 36-45; (4) 46-55; (5) 56-65; and (6) uper 66 years old. The vast majority falls on what can be described as "productive age", namely young or middle aged adults.

Forty percent (40\%) of the interviewees said that they own property near the lagoon, while $58.75 \%$ of them said that they reside or work (even temporarily) near the lagoon. Almost seven out of eight (87.5\%) of the 
interviewees stated that their profession is not related in any way to the lagoon. 58.75\% of interviewees are unmarried, while one of the interviewees refused to answer this question.

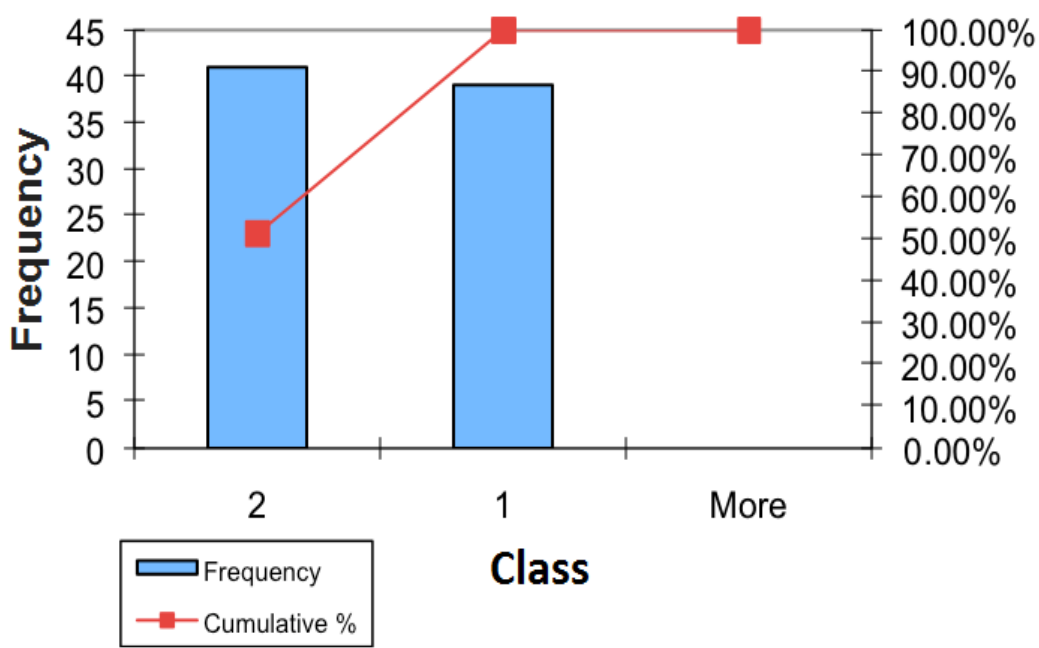

Figure 19. Sexual distribution of the sample. Notes. 1-woman; 2-man.

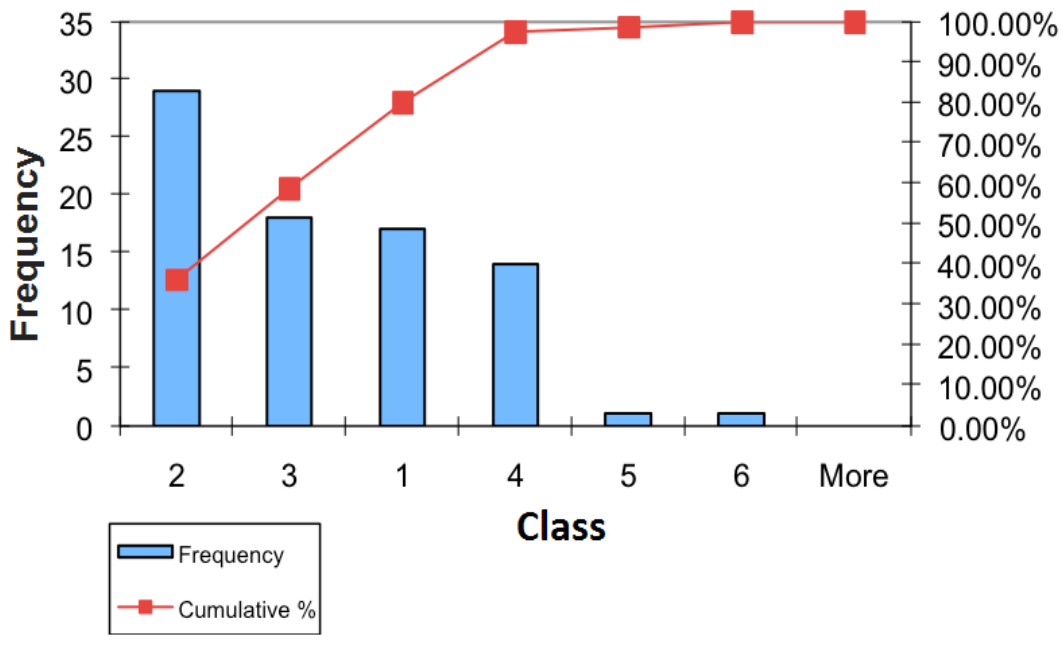

Figure 20. Age distribution of the interviewees. Notes. $1-16-25 ; 2-26-35 ; 3-36-45 ; 4-46-55$; 5-56-65; 6-older than 66 years old.

\section{Conclusions}

For the present analysis, the natural environment was considered as a public good and environmental pollution as an externality that the price mechanism fails to internalize. In all three cases, the non-marketable values were estimated with the WTP method and calculated the external costs generated by the degradation of the environment from the responses of respondents in monetary units. Respondents answered without knowing what the environment's original condition was and without expecting it to return to its original state. The quality of the clean environment and therefore the valuation of external economic burden caused by contamination is not a constant; it is evaluated with personal criteria and the personal endorsement of the value of that public good.

Summarising, the present study revealed that even though the vast majority of the public recognise the 
degradation of the surrounding environment and demand its restoration and remediation, showing willingness to participate toward that goal, yet the fund they are willing to offer to that end is limited and definitely much less than necessary. For a successful and viable restoration, the intervention and financial support of local and central governments is pivotal.

The initial state of the environment is unknown and undefined. Consequently, the degree of alteration of the natural environment from its original state cannot be determined. Human activities and constructions create new values in the region and therefore the external costs can be measured only with an expected level of environmental quality, determined most of the times arbitrarily, assuming that this level is not lost in the process. Allowances, taxation, and value of land use are calculated solely on the expected image of the landscape. Therefore, the Pareto optimal socioeconomic lines status is defined according to the new form of environment created after the regeneration of areas and not according to the initial state of the environment. According to Kaldor, compensation should be determined based on the economic valuation of public goods by the people themselves, who judge based on expectations rather than past data and experience. The expected state of the natural environment varies from respondent to respondent and its approach to social welfare units can only be done through alternative best and worst scenario. In any case, the society wants to reach the minimum point of the charge attributed to pollution and what can be achieved by the "invisible hand", the regulation and government intervention. History has shown that the charge received by the society because of pollution varies with the socioeconomic status of citizens. The lower the income of the residents, the more elastic they appear to the loss of quality of the natural environment. The elasticity of citizens deprived or not by the physical environment is a measurable size.

\section{References}

Allais, M. (1952). Treatise on pure economy. The general background for pure economy. Paris and vol. IV, Annexes (2nd ed. of a textbook published in 1943 under the title A la recherché d'une discipline economique—On the research for an economic discipline).

Auckley, G. (1961). Macroeconomic theory. New York: Macmillan.

Batzias, D. (2010). A dynamic approach to estimating environmental subsidies by combing direct with indirect cost indices. 8th Int. Conf. Comput. Methods Sci. Eng., Kos, Greece, Amer. Inst. Physics.

Batzias, D. F. (2008). Contribution to environmental contingent valuation methodology and case study. ICMMS 2008: Int. Conf. Manage, Marketing Sci, Athens, Greece. UK: Imperial College Press.

Batzias, F. A., \& Markoulaki, E. C. (2002). Restructuring the keywords interface to enhance CAPE knowledge via an intelligent agent. Comp. Aided Chem. Eng., 10, 829-834.

Batzias, F., \& Kopsidas, O. (2010). Introducing a conditional "Willingness to Pay” index as a quantifier for environmental impact assessment. 8th Int. Conf. Comput. Methods Sci. Eng., Kos, Greece, Amer. Inst. Physics.

Bolt, K., Ruta, G., \& Sarraf, M. (2005). Estimating the cost of environmental degradation. Environment Department report, the World Bank. Washington, DC. Retrieved from http://iwlearn.net/publications/misc/caspianev_wbank_manual.pdf

Boulding, K. E. (1966). Economic analysis (Vol. 2). Macroeconomics (4th ed.). New York: Harper \& Row.

Brown, T. C. (2005). Loss aversion without the endowment effect, and other explanations for the WTA-WTP disparity. J. Econ. Behav. Org., 57(3), 367-379.

Liao, T. F. (1994). Interpreting probability models: Logit, probit, and other generalized linear models. Thousand Oaks, CA: Sage Publications.

Menard, S. (2001). Applied logistic regression analysis (2nd ed.). Los Angeles, USA: Sage Publications Inc.

Sarraf, M., Larsen, B., \& Owaygen, M. (2004). Cost of environmental degradation: The case of Lebanon and Tunisia. Environment Department Paper No. 97, the World Bank, Washington, DC. 